\title{
Atribuição de sentidos e agregação de valor: insumos para o Turismo Rural em regiões cafeicultoras ${ }^{1}$
}

\author{
Meanings and value addition: contributions to \\ Rural Tourism in coffee regions
}

\begin{abstract}
Helga Cristina Carvalho de Andrade, Valderí de Castro Alcântara, Ana Paula de Melo Aldano, Antônio Carlos dos Santos
\end{abstract}

\begin{abstract}
RESUMO
O consumo de café tem passado por mudanças em função de novas exigências dos consumidores. Essas mudanças podem ser compreendidas pelas 'ondas de consumo', que segmentam as tendências de consumo do café no tempo. Diferentes sentidos são atribuídos ao café, interferindo diretamente na sua comercialização e possibilitando o surgimento de um turismo rural que tem a cafeicultura como principal insumo. Neste trabalho, objetiva-se, através de um ensaio teórico, identificar os sentidos atribuídos ao café nas distintas fases de consumo e discutir como esses novos sentidos podem servir de insumos para o turismo rural. Foram identificados os seguintes sentidos atribuídos ao café pelos produtores e consumidores: econômico, histórico-social, de socialização, de status, de responsabilidade ambiental, de responsabilidade social, identitário, afetivo e de estilo de vida. Observa-se que a Terceira Onda de Consumo contribui com novos sentidos que estimulam o turismo rural nas origens produtoras e são resignificados pela atividade turística.
\end{abstract}

PALAVRAS-CHAVE: Terceira Onda de Consumo; Sentidos do Café; Agregação de Valor; Turismo Rural.

\section{ABSTRACT}

Coffee consumption has changed due to new necessities demanded by modern consumers. This change can be understood through the concept of the Third Wave of Coffee Consumption. Different values habe been given to the coffee, affecting its marketing and guiding to a new rural tourism, based on coffee as its main factor. In this paper, we aim to identify, in a theoric essay, the meaning given to the coffee during the three waves of coffee consumption, discussing how these new meanings can contribute to rural tourism in producing areas. We identified the following meanings given to coffee by farmers who produce the coffee and consumers of the coffee: economic, social-historical, socialization, status, environmental responsibility, social responsibility, identity, affectional and life style. We found that an understanding of the Third Wave contributes to new meanings that stimulate rural tourism in producing áreas and are, also, rebuilt by tourism.

KEYWORDS: Third Wave; Meanings of Coffee; Value Addiction; Rural Tourism. 


\section{Introdução}

A cafeicultura é uma atividade de grande impacto mundial, seja do ponto de vista econômico, social ou cultural. O café pode ser considerado a commodity agrícola mais importante no mundo (INTERNATIONAL COFFEE ORGANIZATION, 2014). A cafeicultura no Brasil gozou das facilidades do clima propício, da mão de obra barata e da disponibilidade de terras férteis para instalar-se de forma extensiva e com enfoque na produtividade, em detrimento da qualidade do produto. Desde o início da cafeicultura no país em 1727 até o final do século XX essa mecânica produtivista foi adequada à realidade do mercado mundial e fez do café o 'esteio do Brasil' (MARTINS, 2008). No entanto, no final do século $X X$ e, mais fortemente, no século $X X I$, surgiram novas necessidades de consumo, características de uma sociedade que demanda também experiências e não apenas produtos e serviços (LIPOVETSKY, 2007).

No mercado do café essa mudança se fez notar no que ficou conhecida como 'Terceira Onda de Consumo' (SILVA; GUIMARÃES, 2012). Uma evidência dessa nova tendência é o advento dos cafés especiais, que garante um lugar cativo para o café na gastronomia.

Paralelamente ao interesse gastronômico, a busca da completude da experiência de consumir o café gera interesse pela origem produtora. É inevitável, assim, a geração de fluxo turístico para essas origens, com motivações diversas, desde o interesse técnico ou de negócios, até a pura fruição hedônica. Nesse contexto, o turismo se torna um elemento essencial à experiência proporcionada pelo café: como resultado dos valores buscados pela sociedade contemporânea e, ao mesmo tempo, imprimindo novos sentidos e valores sobre a atividade cafeicultora.

Ao mesmo tempo, observa-se um crescente interesse dos produtores rurais em adentrar na atividade turística, atraídos pela expectativa de ganhos adicionais pela associação das atividades de produção e recepção de visitantes. A partir dessas premissas, estes pesquisadores têm por objetivo, neste trabalho, identificar como são percebidos os sentidos atribuídos ao café ao longo das distintas fases de consumo e, ainda, discutir sobre como essas novas atribuições de sentidos pela sociedade contemporânea podem servir de insumos para um turismo rural consciente em regiões cafeicultoras.

Para tanto, este trabalho foi desenvolvido como ensaio teórico, que se refere a uma "relação permanente entre o sujeito e o objeto, um vir-a-ser constituído pela interação da subjetividade com a objetividade dos envolvidos" (MENEGHETTI, 2011, p. 321) e, dessa forma, considera além da literatura acadêmica, as experiências dos pesquisadores. Por conseguinte, a força de um ensaio está atrelada à reflexão sobre a realidade que deve ser conduzida de forma inovadora e criativa (MENEGHETTI, 2011). Com isso a ideia é propor novos diálogos e debates a partir deste ensaio.

\section{As Ondas de Consumo e atribuição de sentidos}

Na década de 1980, Alvin Toffler defendeu em seu livro The Third Wave a existência de fenômenos na economia que denominou 'ondas' 
(TOFFLER, 2007). De acordo com o autor, estes fenômenos podem ser divididos em três ondas: a primeira onda se refere à Revolução Agrícola, a segunda onda à Revolução Industrial e a terceira onda é representada pela Revolução Tecnológica.

Um conceito semelhante foi cunhado pela barista americana Trish Skeie em 2003, e ganhou popularidade no universo do café para descrever um novo estilo de consumo (SILVA; GUIMARÃES, 2012). Sob essa perspectiva, o consumo de café também poderia ser dividido em três ondas.

$\mathrm{Na}$ Primeira Onda de Consumo, situada no período pós-guerras, o café seria consumido pela sua utilidade, mais que pela sua apreciação. As propriedades da cafeína fizeram do café um alimento de consumo diário, levando à massificação da sua comercialização. $O$ café passou a ser um produto de grande valor econômico no comércio mundial, não só nos países com vocação agrícola e com clima apropriado para seu cultivo; também países industrializados se aproveitaram do grande consumo mundial por meio da torrefação dos grãos e do desenvolvimento de tecnologias como o café solúvel. Apesar das exigências de padrão do café, em semelhança a outras commodities, a qualidade não era um item de grande importância, mas sim a produtividade (SILVA; GUIMARÃES, 2012).

A Segunda Onda de Consumo, de acordo com Silva e Guimarães (2012), foi marcada pela melhoria da qualidade dos grãos e pela maior valorização desse diferencial no mercado. $O$ marco desse período é o surgimento das grandes redes de cafeterias como a Starbucks, que difundem ao redor do mundo o consumo de cafés de melhor qualidade, associado ao preparo em máquinas de expresso, bebidas à base de café e ambientes exclusivamente pensados para valorizar o café. Essa onda foi responsável pela sofisticação do hábito de consumir café fora de casa e levou ao consumidor pela primeira vez alguma noção sobre diferentes origens produtoras. Nesse contexto, menciona-se pela primeira vez o termo specialty coffee, ou café especial, cujo primeiro registro data de 1974, quando a industrial norte-americana Erna Knutsen o utilizou para descrever cafés in natura de alta qualidade e de quantidade limitada vendidos por ela a pequenos torrefadores no país (SPECIALTY COFFEE ASSOCIATION OF AMERICA, 2013).

Já a Terceira Onda de Consumo traz sentidos completamente novos para a produção e o serviço do café. A qualidade padronizada da Segunda Onda é substituída pela insaciável necessidade do novo, que recebe como resposta a agregação de valores diferenciados ao café. No Brasil, a tecnologia na produção do café aumentou significativamente nas últimas décadas e, junto a ela, as exigências dos consumidores desse produto (PEREIRA et al., 2004). A possibilidade de diferenciação e segmentação de produtos é um fator de extrema relevância que tem influenciado a competitividade dos produtos agroindustriais. O consumo brasileiro de café se modificou de forma significativa, seguindo as tendências anunciadas anos antes nos mercados mais maduros. Nos Estados Unidos, o mercado de cafés diferenciados surgiu como uma reação do consumidor americano contra a massificação dos produtos, resultando na proliferação de lojas especializadas na venda de cafés especiais. De acordo com os autores, a demanda potencial de cafés no mundo cresceria em proporções 
consideráveis na direção de cafés diferenciados por sua alta qualidade sensorial e sanitária, além da responsabilidade social e ambiental no seu processo produtivo (PEREIRA et al., 2004).

Lipovetsky (2007) relata de forma semelhante um processo que denomina de 'Sociedade do Hiperconsumo'. Este fenômeno, iniciado no final dos anos setenta, começou a ser identificado por especialistas ainda em meados dos anos sessenta, quando a aquisição de produtos, viagens e serviços não podia mais ser explicada a partir apenas do modelo da 'Sociedade de Consumo', que consumia por distinção e status. O consumo responde, a partir dessa época, também a outros ideais: a felicidade privada, lazeres e condutas de consumo menos sujeitas ao julgamento do outro. Para Lipovetsky (2007), o materialismo sai de moda na sociedade contemporânea, dando lugar à expansão do mercado da alma, do equilíbrio e da autoestima.

Pode-se compreender, a partir da análise de distintos modos de consumo, que a mudança de valores modifica também os sentidos atribuídos aos produtos e serviços consumidos. Ressalta-se que o conceito de sentido adotado se refere a um constructo que é subjetivo e socialmente desenvolvido. Dessa forma, o sentido é dinâmico e assim se difere de significado (GÓES; CRUZ, 2006). Portanto, os sentidos atribuídos ao café se referem a uma construção que envolve aspectos sociais, econômicos, culturais e psicológicos relacionados a produção e ao consumo do café. É pressuposto que os sentidos da atividade turística, como aqueles do consumo do café, são múltiplos e não são mutuamente excludentes.

\section{Ambiente Rural e o Turismo na Cafeicultura}

O ambiente rural tradicional deu origem a unidades sociais que possuíam organizações quase autossuficientes, e essa dinâmica social era responsável por reforçar a identidade e o sentimento de pertencimento dessas comunidades. A inserção do camponês na sociedade de mercado através da sua participação nas relações comerciais marca, por sua vez, o início de um rural moderno, cuja dinâmica é influenciada pelas demandas urbanas.

As mudanças no meio rural provocam o despertar da cidade em relação ao campo (CÂNDIDO, 1975; BRANDEMBURG, 2010), representando o rural reconstruído, em que o tradicional não é substituído pelo moderno, mas é ressignificado. O campo, por sua vez, identifica nisso uma oportunidade de negócio, principalmente, nas áreas economicamente estagnadas em função de crises agrárias.

[...] a demanda gerada a partir dessas necessidades deixou evidente que os recursos existentes dentro das propriedades que até então estavam voltados para atender as necessidades do setor primário da economia nas atividades de agricultura e pecuária eram passíveis de aproveitamento turístico (FUCKS; SOUZA, 2010, p. 97). 
Segundo o Ministério do Turismo (BRASIL, 2003), o turismo rural é um segmento de extrema importância para o Brasil proporcionando desenvolvimento rural. Ele é definido como "o conjunto de atividades turísticas desenvolvidas no meio rural, comprometido com a produção agropecuária, agregando valor a produtos e serviços, resgatando e promovendo o patrimônio cultural e natural da comunidade" (BRASIL, 2003, p. 11). Segundo Andrade, Alcântara e Gonçalves (2014, p. 2) "além de Turismo Rural, outras terminologias são utilizadas no país para designar atividades de turismo em áreas rurais, como turismo de interior, turismo endógeno, campestre, sertanejo, agroturismo, entre outros".

Há certa dificuldade em se conceber um conceito universal de turismo rural, que não raro é incorporado a outras modalidades, convertendo-se em um mix de ecoturismo, turismo verde, turismo cultural (ARAÚJO, 2010) e agroturismo. A Associação Brasileira de Turismo Rural (ABRATURR) define o turismo rural como "atividade multidisciplinar que se realiza no meio ambiente, fora de área intensamente urbanizada. Caracteriza-se por empresas turísticas de pequeno porte, que tem no uso da terra a atividade econômica predominante voltada para práticas agrícolas e pecuárias" (SILVA et al., 1998, p. 14).

Dentro dessa proposta, o turismo rural pode ser entendido como uma prática que envolve atividades ao ar livre, vivência da vida no campo, gastronomia regional, artesanato e produtos, em um contexto que faça do visitante mais que mero expectador. O consumidor deseja aprender sobre os processos de produção, sobre a cultura e, principalmente anseia por interagir com esse ambiente.

O turismo rural possui como arcabouço a valorização dos aspectos tangíveis e intangíveis do patrimônio, da paisagem e da cultura no meio rural. E é esse sentido de valor que promove o envolvimento das comunidades agrícolas em prol do desenvolvimento do turismo. Isso pode ser percebido através dos mecanismos de reforço da identidade e da sua relação com o territorio. Fato é que o turismo necessita desses elementos de memória, ou até mesmo de reinventar a sua memória para que haja a conservação das manifestações e dos produtos culturais (FUCKS;SOUZA, 2010; ARAÚJO, 2010; TULIK, 2010).

Esta modalidade de turismo é importante na geração de postos de trabalho e renda no meio rural (BRASIL, 2003). Em destaque, esse trabalho considera a possibilidade de gerar valor turísticos a partir dos novos sentidos atribuídos ao café pelos produtores e consumidores do produto. Segundo Soares e Vieira Filho (2008, p. 52) "o uso do patrimônio pelo turismo pode trazer a oportunidade de preservação das fazendas históricas e de toda a riqueza histórica do café no Brasil, para que esta e as futuras gerações percebam a importância do patrimônio e da memória do país".

O Turismo no Espaço Rural pode se desenvolver com a união de diversas atividades, os apelos culturais de patrimônio histórico, a memória e a identificação de pertencimento a história do país podem ser percebidas nas construções históricas das Fazendas de Café, que permitem a prática do Turismo Cultural. Segundo Cavalcanti (1992) o 
turismo cultural não é só o legado que é herdado, é também o legado que, através de uma seleção consciente, um grupo significativo da população deseja levar ao futuro. Ou seja, existe uma escolha cultural subjacente à vontade de levar o patrimônio cultural a gerações futuras (SOARES; VIEIRA FILHO, 2008, p. 50).

No Brasil, uma destas práticas com o café ocorre quando as fazendas abrem suas portas para o turismo. Um exemplo são as "Fazendas Históricas Paulistas" (FAZENDAS PAULISTAS, 2015).

É necessário refletir sobre a natureza de um turismo no café: as motivações dos turistas se confundem e possibilitam o enquadramento da atividade em diferentes tipologias de turismo, mas possuem em comum um elemento essencial, que é a descoberta de um "mundo de trabalho", seus lugares, técnicas, organizações e culturas (DAMIEN; SOBRY, 2001). Seguramente, uma abordagem delineada por esse saber-fazer na cafeicultura será de grande utilidade para o entendimento do fenômeno turístico no agronegócio, podendo representar um ensaio para a futura ordenação e identidade do turismo do café no Brasil, a exemplo das práticas turísticas já emblemáticas em outros países produtores.

\section{Atribuição de sentidos e agregação de valor ao café}

A partir da revisão bibliográfica e da própria experiência dos autores em regiões e propriedades cafeicultoras, bem como da análise do mercado cafeeiro, pode-se identificar os principais sentidos atribuídos ao café pelos produtores e consumidores do produto. Também foi possível compreender a evolução, manutenção e modificação desses sentidos no decorrer das diferentes Ondas de Consumo identificadas (Figura 1, próxima página).

Desde que foi introduzido nas colônias tropicais europeias ao redor do mundo, o café possui sentido de valor econômico. Em grande parte dos territórios adequados ao seu cultivo, a cafeicultura se tornou principal fonte de renda das comunidades rurais, gerando forte dependência econômica. Os países colonizadores enriqueceram-se por meio da comercialização do produto in natura e, mais tarde, da sua industrialização. Durante a Primeira Onda de Consumo, as formas práticas de consumo se valorizam, em função das necessidades criadas nas grandes guerras e do surgimento do café solúvel. Já na Segunda Onda, com o surgimento do conceito de 'café especial' e das redes de cafeteria, as exigências do mercado se focam na qualidade do produto, realizando uma maior discriminação entre os cafés de diferentes origens por sua qualidade; nesse período, a rastreabilidade do café ainda não apresenta tanta importância, mas sim o padrão do produto. Já na Terceira Onda, o novo padrão de consumo exige conhecimento da origem, das práticas produtivas e da identidade do café, e a diferenciação passa a remunerar melhor produtores que conseguem manter essa identidade e oferecê-la a mercados maduros, primeiramente no exterior e, mais recentemente, nos próprios países cafeicultores. 


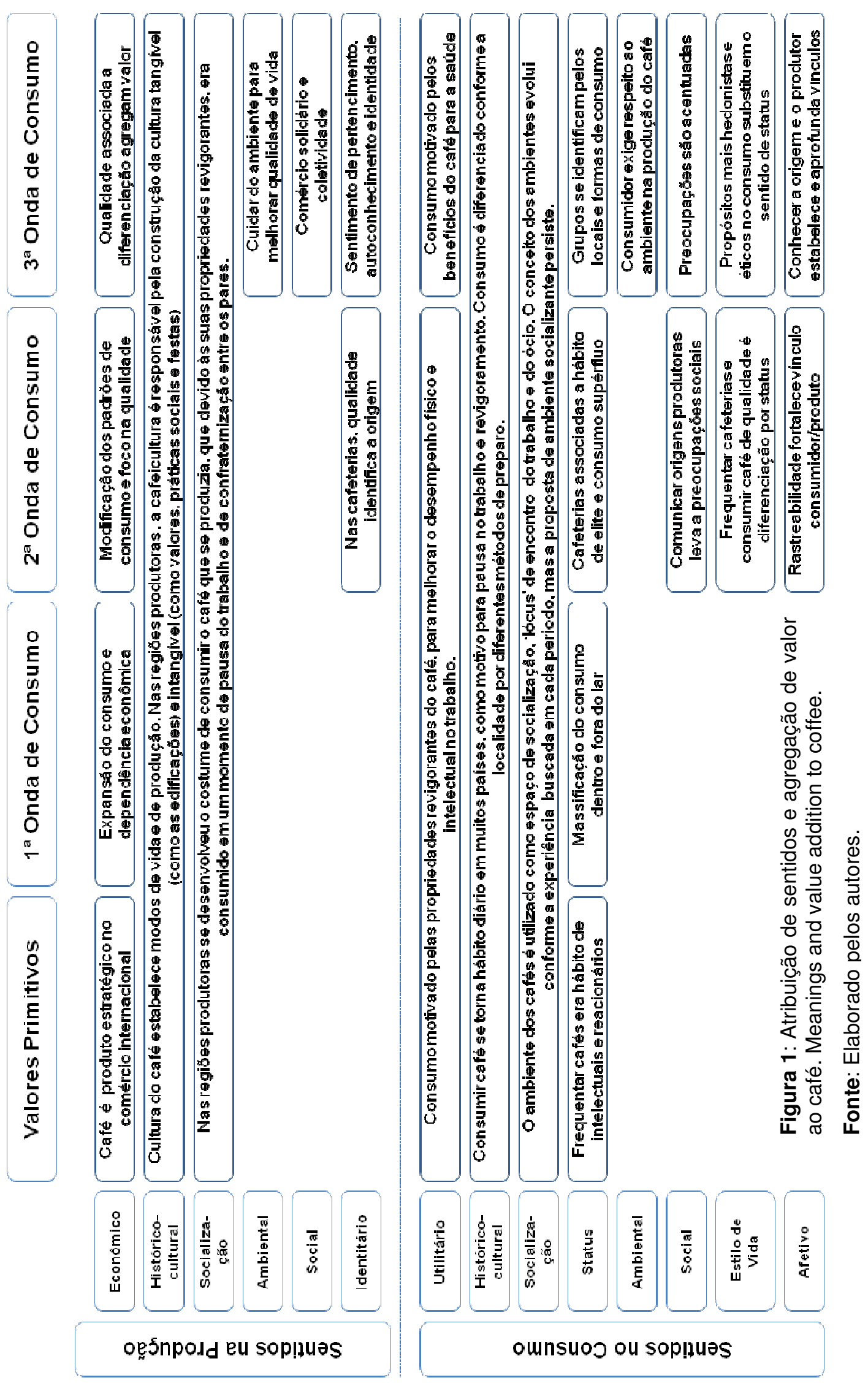


Do ponto de vista do consumidor, o café possuía sentido utilitário, na medida em que servia ao propósito de melhorar a concentração e o desempenho físico e intectual no trabalho. O consumo se dá mais pela utilidade da bebida do que pela sua apreciação, na Primeira Onda de Consumo. Na Segunda Onda, persiste essa motivação de consumo, em paralelo aos novos sentidos trazidos pela melhoria da qualidade. Já na Terceira Onda de Consumo, a ciência aponta novas utilidades para o café, além do efeito da cafeína, e a bebida passa a ser consumida também pelo seu valor nutricional.

A dependência econômica da produção do café resultou, nas regiões produtoras, em um patrimônio cultural constituído em função da cafeicultura. Conforme observam Andrade e Moss (2012), a cafeicultura assumiu forte sentido de valor histórico-cultural, na medida em que ultrapassa o modo produtivo, influenciando a vida em comunidade, as tradições e a modificação da paisagem. Um exemplo dessa influência é o Eixo Cafeeiro na Colômbia, região produtora que recebe grande fluxo turístico:

O cultivo do café na Colômbia é uma herança da colonização antioquenha, e deixou como legado um conjunto de tradições e manifestações culturais, entre as quais podem ser destacadas as festas nacionais do café e da colheita; o artesanato, em que sobressaem motivos relacionados ao café e também produtos comestíveis como conservas, bolo de rolo, pamonha, rapadura e outros derivados de cana; gastronomia representada pelas comidas de montanha, características por sua quantidade, modo de preparo, apresentação, cores e estética; a presença da mula, principal veículo de carga; e o vestuário típico com uso do chapéu, poncho, manta e embornal (ANDRADE; MOSS, 2012, p. 519).

Nos mercados consumidores, o café também imprimiu grande influência na cultura. As preferências de consumo variam nas diversas partes do mundo, desde a característica sensorial do café (tipo de grão, ponto de torra) até os métodos de preparo e consumo (filtrado, extraído sob pressão, bebido puro, com leite ou açúcar). $O$ ato de consumir café funciona como momento de pausa, revigoramento e confraternização. Essa influência é tamanha que, em muitos idiomas, a palavra "café" é utilizada para designar a refeição matinal (café da manhã) e as pequenas refeições ao longo do dia (café da tarde, intervalo para café). Esse sentido de valor cultural pode ser observado desde o início do consumo de café no mundo e perdura em todas as Ondas de Consumo.

As propriedades revigorantes da cafeína e a própria temperatura da bebida favorecem a necessidade de pausa que acompanha o consumo do café. Essa pausa representa um sentido de socialização, que se faz presente tanto nas regiões produtoras quanto no universo do consumidor. $O$ café parece exigir o comensalismo, a confraternização entre os pares, além de permitir resultados satisfatórios na concentração para o trabalho e negócios, ao mesmo tempo em que acompanha o ócio compartilhado. Esse 
sentido permanece presente em todas as Ondas de Consumo, e é revitalizado na Terceira Onda.

Tanto o produto quanto o ambiente de consumo do café fora do lar manifestam um sentido de status, pela diferenciação de grupos ao longo da evolução do consumo. No período que coincide com o lluminismo e também mais tarde nos países colonizados, frequentar casas de café era um hábito de intelectuais, artistas e reacionários, e este ambiente era lócus da idealização de grandes revoluções e mudanças sociais, como a Revolução Francesa e o Modernismo no Brasil. Na Primeira Onda de Consumo, a massificação do produto reduz o sentido de status, que é recuperado na Segunda Onda, mais uma vez por meio dos espaços das cafeterias. Nesse período, o consumo de café em cafeterias representa luxo e sofisticação, até que mais tarde os novos padrões mínimos de qualidade são, de certa forma, novamente massificados. Na Terceira Onda, por sua vez, o consumo de café de diferentes qualidades e formas de preparo distingue novamente os grupos sociais, mas dessa vez por seus valores e identidade, e não somente pelo seu poder econômico.

O sentido de responsabilidade ambiental provavelmente teve seus primeiros indícios ainda na Segunda Onda de Consumo, devido às conferências mundiais em torno da temática que ocorreram a partir da década de setenta (SACHS, 2004). No entanto, somente da Terceira Onda de Consumo essa preocupação adquire força e torna-se decisiva no mercado de café. Do ponto de vista do consumidor, surgem preocupações sobre o respeito ao meio ambiente no processo produtivo e na distribuição do produto, o que ganha força com a rastreabilidade do café. Para atender seus clientes, muitos empresários do setor passam a buscar informações mais detalhadas sobre as origens e os produtores, o que estabelece relação mais próxima entre os elos da cadeia produtiva. Ganham força as certificações ambientais e o cultivo orgânico como garantia de responsabilidade ambiental para o consumidor. Do ponto de vista do produtor, sua sobrevivência no mercado passa a depender da sua capacidade de atender a estas demandas, o que provoca uma verdadeira revolução nas práticas produtivas.

De forma semelhante ao sentido de responsabilidade ambiental, os mercados mais maduros passam a exigir dos seus fornecedores práticas de que se adequassem a um sentido de responsabilidade social, marcado principalmente pela remuneração adequada dos cafeicultores. Na Terceira Onda consolida-se o comércio solidário e o comércio direto, com a eliminação de intermediários e aproximação dos elos da cadeia produtiva. Entre os produtores, a busca pela certificação e mesmo por ganhos de escala fortalece a ação coletiva e dá origem a redes de cooperação.

Também se pode perceber, a partir da Segunda Onda de Consumo, o despertar de um sentido de identidade nos produtores de café. Esse sentido é atribuído em função da exigência de qualidade do mercado, que passa a diferenciar as regiões produtoras ou os produtores com capacidade de fornecer grãos com altos padrões. A partir da Terceira Onda de Consumo, nota-se a expansão desse sentido de identidade, que aumenta a percepção de pertencimento dos produtores rurais a uma localidade única por seu ambiente e seu fator humano. A escolha das práticas agrícolas, a 
participação ativa em grupos de governança compartilhada, entre outros, são evidências desse sentido nas regiões produtoras.

Em contrapartida, a rastreabilidade do produto aprofunda o interesse dos consumidores pela origem, e estes passam a estabelecer um sentido afetivo com o produto e com o cafeicultor ou comunidade que o produz. Esse vínculo estabelecido com a região origina preferências de consumo que não são motivadas somente pela qualidade intrínseca do produto, mas pela experiência resultante das relações estabelecidas entre produtor e consumidor e, posteriormente, com a aproximação do consumidor à origem, entre visitado e visitante.

Finalmente, se observa a criação de um sentido de estilo de vida, que resulta de um conjunto de valores característico de um indivíduo ou grupo, e que têm relação íntima com os ideais da sociedade do hiperconsumo. O que se busca é a prática hedônica, o prazer e a felicidade na experiência de consumo, que é resultante também de uma coerência ética nas práticas de consumo escolhidas.

\section{Acerca da experiência no café e da contribuição do turismo rural}

A Terceira Onda de Consumo acrescenta novos sentidos ao consumo do café que, se por um lado reflete exigências do mercado consumidor, por outro provoca mudanças na estrutura de produção e no ambiente rural. Enquanto a Primeira e a Segunda Ondas refletem o rural moderno, voltado para as necessidades objetivas da sociedade de consumo, a Terceira Onda coincide com o rural reconstruído, que recupera aspectos do rural tradicional ao mesmo tempo em que o resignifica. Essa ressignificação é perceptível na atribuição de sentido de identidade, pelo produtor, e afetividade pelo consumidor. Esse consumidor se torna, por sua vez, visitante, estimulado pela vontade de retomar o vínculo com o meio rural, conhecendo a origem daquilo que consome.

Nas origens produtoras, antes focadas em produzir e escoar sua produção para os melhores mercados, os cafeicultores percebem que o consumidor pode ir até o produto, o que consiste em uma oportunidade de comércio direto e, consequentemente, melhor margem de remuneração. Além disso, a chegada do visitante incentiva a verticalização das propriedades ou comunidades produtoras, já que a presença do alóctone ávido por informação e experiência demanda o produto acabado, para ser consumido no local em que é produzido, conjugando "a curiosidade sobre a produção alimentar e o desejo de consumir gêneros em sua atmosfera de origem" (ANDRADE; MOSS, 2012). Segundo Schluter (2003), a demanda pelo consumo dos produtos no local de origem impulsiona um tipo de turismo motivado pela experiência gastronômica. $O$ desenvolvimento de produtos turísticos com essa temática atende ao propósito de incentivar o consumo daqueles produtos que existem em abundância no destino turístico ou valorizar produtos dos quais as comunidades dependem fortemente, promovendo, assim a agregação de valor ao produto e contribuindo para o desenvolvimento em áreas rurais (ANDRADE; MOSS, 2012), a exemplo do que vem ocorrendo com a cafeicultura. 
A agregação de valor ao café, em associação com o sentido de identidade alimentado pelos cafeicultores com seu produto, forma de trabalho e meio produtivo, é capaz de promover no campo a compreensão da qualidade café, que tanto é exigida pelo mercado, mas, na prática, sempre esteve fora do entendimento da maioria dos produtores. As relações diretas estabelecidas entre produtor e empresários situados na outra ponta da cadeia, a busca da certificação das propriedades e a presença de consumidores na propriedade rural exercem um verdadeiro papel de emancipação do produtor, na medida em que lhe permitem compreender as demandas do mercado, conhecer a fundo o seu produto e refletir sobre o impacto causado pelas suas decisões no processo produtivo. Esse efeito emancipatório é ainda mais evidente na cafeicultura familiar, e representa também o empoderamento das comunidades cafeicultoras, na medida em que leva à apropriação da informação e vislumbra uma possibilidade real do cafeicultor interferir no seu mercado, e consequentemente, na sua participação na cadeia produtiva no futuro.

Com relação ao fluxo turístico para regiões cafeicultoras, observam-se três grandes tendências. A primeira se refere a um turismo de negócios, que ocorre em função da necessidade que os compradores de café dos mercados mais maduros apresentam de conhecer a origem, rastrear 0 processo produtivo e certificar que o produto atende às necessidades do seu segmento de clientes.

Uma segunda tendência atende a motivações mais técnicas e acontece com grande frequência em regiões apontadas por sua excelência em questões como a governança coletiva, tecnologia de produção e qualidade do produto. Esse turismo, que pode ser caracterizado como um turismo do saber fazer, ou turismo agroindustrial, é realizado por pesquisadores, profissionais posicionados em diversos estágios da cadeia produtiva e, inclusive, por cafeicultores interessados em conhecer as práticas de excelência em outras regiões. Exemplos de destinos que já recebem visitantes com estas motivações são Poço Fundo (MG), em que grande parte dos produtores se organizam em torno da certificação orgânica e de comércio solidário (SOUZA; BORÉM; ALVES, 2014), e a Região do Cerrado Mineiro, primeira Indicação Geográfica brasileira a possuir a Denominação de Origem para o produto café (LEME et al., 2013).

Outra tendência é marcada pela prática do turismo rural per se, cuja motivação ocorre pela busca de experiências que conjuguem o lazer com possibilidades de aprendizado. Visitantes com esse tipo de motivação podem ser encontrados em destinos como o eixo cafeeiro na Colômbia (ANDRADE; MOSS, 2012) e Venda Nova do Imigrante (MG), que oferecem vivências lúdicas ambientadas em propriedades cafeicultoras.

\section{Considerações Finais}

Neste ensaio, buscou-se identificar os sentidos atribuídos ao café ao longo das distintas fases de consumo e a relação desses sentidos com a incorporação do turismo rural à cultura do café. Pode-se observar que os sentidos do café se modificam em cada Onda de Consumo, e utilizar essa 
referência temporal é de grande utilidade para a compreensão das mudanças ocorridas no mercado de café.

A Terceira Onda de Consumo é marcada pela ressignificação tanto do produto café quanto do ambiente rural, e coincide com o surgimento do interesse pelas origens produtoras e o aumento do fluxo turístico para essas regiões. Os autores deste trabalho defendem que conhecer os sentidos atribuídos para o produto café por determinado nicho de mercado pode representar uma vantagem competitiva frente a esses mercados, e possibilitar a oferta de experiências turísticas que atendam a essas demandas de forma eficiente.

De maneira semelhante, conhecer os sentidos atribuídos pelos cafeicultores ao seu produto e ao seu ambiente pode servir de insumo estratégico para o desenvolvimento de produtos turísticos mais coerentes com a identidade dos destinos e auxiliar na elaboração de políticas mais assertivas para incentivar o turismo consciente em regiões produtoras.

Compreende-se que, pelo caráter de ensaio, este trabalho possui a limitação de não apresentar uma pesquisa sistemática que corrobore os tipos de sentidos propostos. No entanto, essa perspectiva demonstra o caráter inovador do estudo e descortina uma agenda de pesquisas que possam confirmar ou refutar os sentidos atribuídos em cada onda de consumo, especialmente pesquisas de natureza qualitativa.

\section{Referências bibliográficas}

ANDRADE, H.C.C.; ALCÂNTARA, V.C.; GONÇALVES, J.S. Revisão bibliográfica sistemática preliminar sobre o campo de turismo rural. In: XIII Encontro Nacional de Turismo de Base Local. Minas Gerais, 2014. Anais... Juiz de Fora: Encontro Nacional de Turismo de Base Local, 2014.

ANDRADE, H.C.C.; MOSS, M.C.B. A cafeicultura familiar e um possível modelo para o desenvolvimento do turismo do café em Minas Gerais. Revista Brasileira de Ecoturismo, n.5, v.3, p.512-529, 2012.

ARAÚJO, J.G.F. Potencialidades do turismo no espaço rural: desenvolvimento, conceitos e tipologia. In: SANTOS, E. O.; SOUZA, M. (Orgs.). Teoria e prática do turismo rural no espaço rural. Barueri: Manole, 2010, p. 24-32.

BRANDEMBURG, A. Do rural tradicional ao rural socioambiental. Ambiente \& Sociedade, v.13, n.2, p. 417-428, 2010.

BRASIL. Ministério do Turismo. Diretrizes ara o desenvolvimento do Turismo rural: o Brasil. / Ministério do Turismo, Secretaria Nacional de Políticas de Turismo, Departamento de Estruturação, Articulação e Ordenamento Turístico, Coordenação Geral de Segmentação. - Brasília: Ministério do Turismo, 2003.

CÂNDIDO, A. Os parceiros do Rio Bonito. São Paulo: Duas Cidades, 1975.

SOBRY, C.; DAMIEN, M-M. Le Tourisme Industriel: Le Tourisme Du SavoirFaire. Paris: Harmattan, 2001.

FAZENDAS HISTÓRICAS PAULISTAS. Disponível em: <http://www.fazendaspaulistas.com.br>. Acesso em 19 de maio de 2015. 
FUCKS, P.M.; SOUZA, M. Turismo no espaço rural e preservação do patrimônio, da paisagem e da cultura. In: SANTOS, E. O.; SOUZA, M. (Orgs.). Teoria e prática do turismo rural no espaço rural. Barueri: Manole, 2010, p. 96-108.

GÓES, M.C.R.; CRUZ, M.N. Sentido, significado e conceito: notas sobre as contribuições de Lev Vigotski. Pro-Posições, v.17, n.50, p. 31-45, 2006.

INTERNATIONAL COFFEE ORGANIZATION. Exporting countries: total production. 2014. Disponível em: http://www.ico.org/prices/po.html. Acesso em: 15 mar. 2014.

LEME, P.H.M.V.; ANDRADE, H.C.C.; GADIA, R.M.; REZENDE D.C. Pode a história de um aglomerado produtivo revelar a prática da estratégia? Analisando a convergência estratégica no Cerrado Mineiro. Anais... Colóquio de Redes, Estratégia e Inovação, Lavras: Minas Gerais, UFLA, 2013.

LIPOVETSKY, G. A felicidade paradoxal: ensaio sobre a sociedade de hiperconsumo. São Paulo: Companhia das Letras, 2007.

MARTINS, A. L. História do café. São Paulo: Contexto, 2008.

MENEGHETTI, F.K. O que é um Ensaio-Teórico? Revista de Administração Contemporânea, n.15, v.2, p. 320-332, 2011.

PEREIRA, S.P.; BARTHOLO, G.F.; GUIMARÃES, P.T.G. Cafés especiais: iniciativas brasileiras e tendências de consumo. Belo Horizonte: EPAMIG, 2004.

SACHS, I. Caminhos para o desenvolvimento sustentável. Rio de Janeiro: Garamond, 2002.

SILVA, E.C.; GUIMARÃES, E.R. A Terceira Onda do Consumo de Café. 2012. Disponível em: http://www.icafebr.com.br/publicacao/Terceira\%200nda.pdf. Acesso em: 15 mar. 2014.

SILVA, J. G.; VILARINHO, C.; DALE, P. J. Turismo em áreas rurais: suas possibilidades e limitações no Brasil. In: ALMEIDA, J. A. et al. (Orgs). Turismo rural e desenvolvimento sustentável. UFSM: Santa Maria, 1998, p. 12-18.

SOARES, G.M.; VIEIRA FILHO, N.A.Q. As Fazendas dos Barões do Café no Brasil: Patrimônio Histórico Rural e Turismo. Reuna, v.13, n.3, p.41-53, 2008.

SOUZA, K.R.; BORÉM, R.A.T.; ALVES, H.M.R. Turismo rural: alternativa de melhoria para a agricultura familiar do Sul de Minas Gerais. Revista Brasileira de Ecoturismo, v.6, n.5, p. 990-1015, 2014.

SPECIALTY COFFEE ASSOCIATION OF AMERICA. History. 2014. Disponível em: http://scaa.org/?page=history. Acesso em: 15 mar. 2014.

TOFFLER, A. A terceira onda. 29. ed. Rio de Janeiro: Record, 2007.

TULIK, O. Turismo e desenvolvimento no espaço rural: Abordagens conceituais e Tipologias. In: SANTOS, E. O.; SOUZA, M. (Orgs.). Teoria e prática do turismo rural no espaço rural. Barueri: Manole, 2010, p. 1-22.

Nota:

1 Trabalho apresentado anteriormente no Congresso Brasileiro de Turismo Rural e Desenvolvimento Sustentável (CITURDES 2014). 
Helga Cristina Carvalho de Andrade: Universidade Federal de Lavras, Lavras, MG, Brasil.

E-mail: helga.barista@gmail.com.

Link para o Lattes: http://lattes.cnpq.br/0480370402754934

Valderí de Castro Alcântara: Universidade Federal de Lavras, Lavras, MG, Brasil.

E-mail: valderi.alcantara@posgrad.ufla.br.

Link para o currículo Lattes: http://lattes.cnpq.br/2870598651094370

Ana Paula de Melo Aldano: Universidade Federal de Ouro Preto, Ouro Preto, MG, Brasil.

E-mail: nanedemelo@gmail.com.

Link para o currículo Lattes: http://lattes.cnpq.br/8987463443087612

Antônio Carlos dos Santos: Universidade Federal de Lavras, Lavras, MG, Brasil.

E-mail: acsantos@dae.ufla.br.

Link para o Lattes: http://lattes.cnpq.br/1386863217179570

Data de submissão: 10 de fevereiro de 2015

Data de recebimento de correções: 12 de maio de 2015

Data do aceite: 21 de maio de 2015

Avaliado anonimamente 